\title{
Modelling the exposure of firefighters to smoke based on measured data
}

\author{
A. I. Miranda ${ }^{1}$, J. H. Amorim ${ }^{1}$, V. Martins ${ }^{1}$, P. Cascão ${ }^{1}$, J. Valente $^{1}$, \\ R. Ottmar ${ }^{2}$, L. M. Ribeiro ${ }^{3}$, D. X. Viegas ${ }^{3}$ \& C. Borrego ${ }^{1}$ \\ ${ }^{1}$ CESAM and Department of Environment and Planning, \\ University of Aveiro, Portugal \\ ${ }^{2}$ Pacific Wildland Fire Sciences Laboratory, \\ US Forest Service Pacific Northwest Research Station, Seattle, USA \\ ${ }^{3}$ Association for the Development of Industrial Aerodynamics, \\ University of Coimbra, Portugal
}

\begin{abstract}
This work addresses the exposure of firefighters to carbon monoxide (CO) contained in smoke. We have measured the time and space variation of firefighters' exposure to $\mathrm{CO}$ concentration levels during a real scale fire experiment. A model for the estimation of personal exposure of firefighters to smoke was developed. Based on the combination of georeferenced location of a firefighter and on computed air quality levels the model calculates the individual exposure for a given period. Good agreement was found between estimated and measured averaged exposure during the fire experiments.

The information on the individual exposure of firefighters can support the management of the crew positioning by anticipating potentially critical exposure levels and recommending safer routes for the attack.

Keywords: forest firefighting, smoke emissions, individual exposure, safety, exposure measurement, exposure modelling.
\end{abstract}

\section{Introduction}

Forest fires are a massive source of air pollutants to the atmosphere causing several environmental and human impacts from local to global scales. At the operational level, firefighters are confronted with extremely severe conditions, as steep terrain, falling debris, obstructions to movement, heavy equipment, high 
temperatures, reduced visibility and toxic atmosphere. In this context, carbon monoxide (CO) and particulate matter (PM) are among the air pollutants with the most significant effects over the safety of the personnel in the terrain e.g. [1-3].

Health effects of smoke are the result of a chain of events, going from the release of pollutants leading to an ambient atmospheric concentration, over the personal exposure, uptake, and resulting internal dose to the subsequent health effect. Human exposure refers to the individual contact (not uptake) with a pollutant concentration. Exposure studies can be carried out aiming to estimate exposure of one individual (personal exposure) or of a larger population group (population exposure), through direct or indirect methods. Direct methods are measurements made by personal portable exposure monitors. When using indirect methods, the exposure is determined by combining information about the time spent in specific locations, called microenvironments, and the pollutants concentrations at these same places. Hence, total exposure is the sum of the exposure in all micro-environments during the time of interest.

The current state of knowledge in firefighters' exposure to smoke is notably scarce, in particular in what refers to exposure studies carried out in the European context. The difficulty involved in the monitoring or modelling of the personal exposure to smoke during firefighting activities has largely contributed to this scientific gap.

In this context, the main goal of this work is to provide, through measurement techniques and a modelling procedure, a better understanding of the exposure of firefighters to heavy concentrations of air pollutants contained in smoke.

\section{Field campaign to directly measure exposure}

The experimental fire study area is located in the mountain range of Lousã, Central Portugal $\left(40^{\circ} 15^{\prime} \mathrm{N},-8^{\circ} 10^{\prime} \mathrm{W}\right)$, at an elevation of approximately $1,000 \mathrm{~m}$. In the spring of 2008 seven experimental plots have been burnt aiming to measure fire related characteristics including smoke concentrations and firefighters' exposure. These experimental burning plots were established within Forest Service lands, and within the Gestosa forestry perimeter. The vegetation of the area was mainly composed by continuous shrubs of three dominant species: Erica umbellata, Ulex minor and Chamaespartium tridentatum. Figure 1 shows a schematic representation of the layout of 2008 plots.

Air quality and meteorological data were acquired near the plots during the fire experiments. The location of the laboratorial mobile van measuring air quality levels is highlighted in Figure 1 with a black arrow. The measured pollutants were particulate matter with an equivalent diameter lesser than $10 \mu \mathrm{m}$, nitrogen oxides and CO. Figure 2 presents the temporal evolution of 15 minutes averaged $\mathrm{CO}$ values registered during the experiments. 


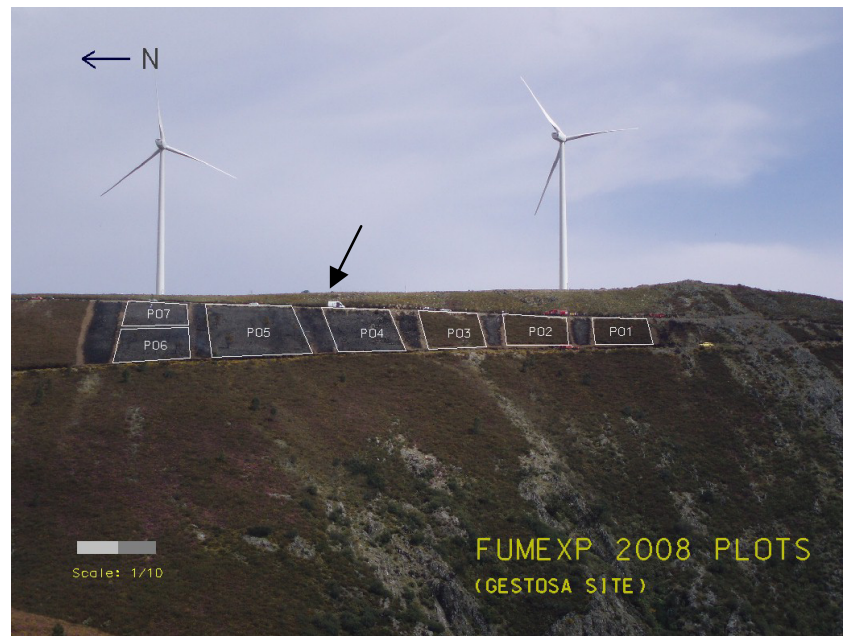

Figure 1: Experimental plots location and layout (the black arrow indicates the location of the laboratorial measuring air quality van).

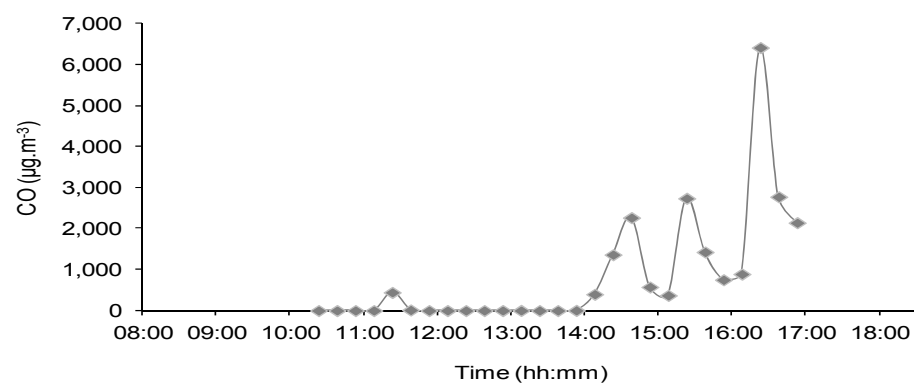

Figure 2: $\quad$ Fifteen minutes averages for $\mathrm{CO}$ concentration values measured with the mobile air quality laboratory during Gestosa 2008 experiments.

The smoke coming from the burning plots affected more intensively the measured data around 16h30, which coincides with the plot P02 burning period. Thus this was the plot selected for further exposure analysis. Its main physical characteristics are described in Table 1, as well as the ignition time and burning end.

Table 1: $\quad$ Main characteristics of the experimental burnt plot P02.

\begin{tabular}{|c|c|c|c|c|c|c|c|c|}
\hline \multirow[b]{2}{*}{ Plot } & \multirow[b]{2}{*}{$\begin{array}{l}\text { Area } \\
\left(\mathrm{m}^{2}\right)\end{array}$} & \multirow{2}{*}{$\begin{array}{c}\text { Slope } \\
\left({ }^{\circ}\right)\end{array}$} & \multirow{2}{*}{$\begin{array}{c}\text { Fuel } \\
\text { coverage } \\
(\%)\end{array}$} & \multirow{2}{*}{$\begin{array}{l}\text { Fuel } \\
\text { height } \\
(\mathrm{cm})\end{array}$} & \multirow{2}{*}{ 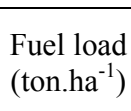 } & \multicolumn{2}{|c|}{ Burning } & \multirow[b]{2}{*}{ Date } \\
\hline & & & & & & Start & End & \\
\hline P02 & 959 & 27 & 100 & 93 & 26.7 & $16 \mathrm{~h} 34$ & $16 \mathrm{~h} 42$ & $06 / 05 / 2008$ \\
\hline
\end{tabular}


Two linear ignitions on the top left side and a third linear ignition along the bottom boundary were used to start the burning, which lasted for 8 minutes.

Three firefighters were equipped with a personal monitoring device for $\mathrm{CO}$ and one Global Positioning System (GPS). Criteria for the selection of these equipments were their toughness, weight, possibility of continuous data acquisition and the easiness of operation. The portable analyser used for the measurement of the concentration of $\mathrm{CO}$ is the GasAlertExtreme, from $B W$ Technologies, with a measuring range of $0-1,000 \mathrm{ppm}$ and a resolution of $1 \mathrm{ppm}$.

More information about the monitoring devices can be found in Miranda et al. [3].

The spatiotemporal routes of the 3 firefighters, as tracked by the GPS equipments are shown in Figure 3. Figure 3 also shows a picture of the smoke plume during the burning of plot P02.

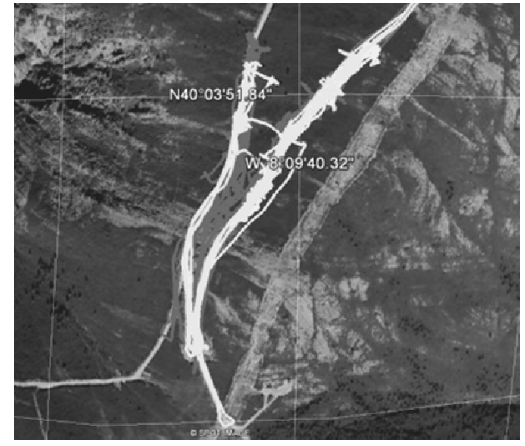

a)

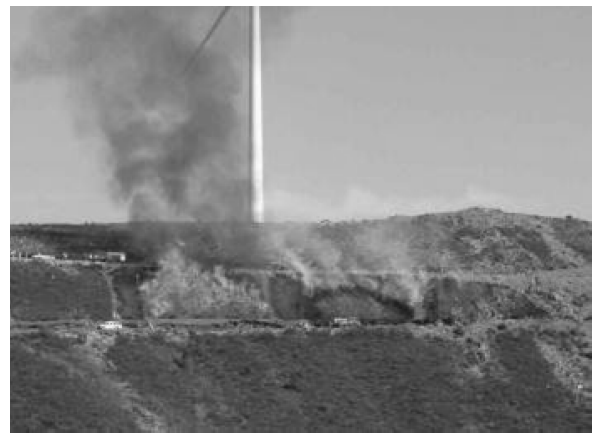

b)

Figure 3: Two perspectives of the fire experiments: a) GPS tracking of the 3 firefighters; b) smoke plume from plot P02 burning.

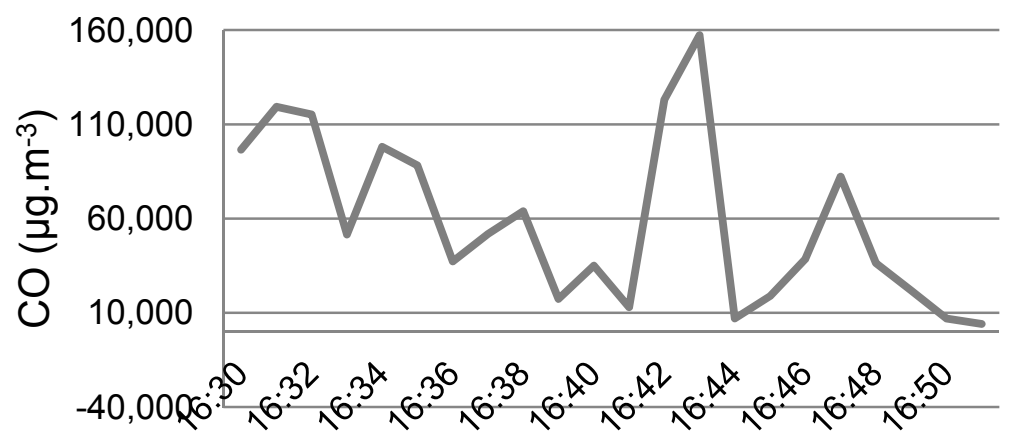

Figure 4: Temporal evolution of measured $\mathrm{CO}$ values for a specific firefigher and during plot P02 burning.

From the three firefighters with GPS and CO monitors only one was exposed to significant $\mathrm{CO}$ values during the plot P02 experiment. His data will be used to 
evaluate the exposure modelling system developed to firefighter activities. The temporal variation of exposure measured data for this particular firefighter and this particular experimental plot P02 is presented in Figure 4.

This firefighter, as well as his crew, occupied positions along the top boundary of the plot; measured values indicate exposure to very high peak values of carbon monoxide, with a maximum value at the end of the burning when mop-up activities were going on. Mop-up smoke emissions are mainly characterised as smoldering compounds, such as $\mathrm{CO}$.

\section{Smoke exposure model development}

For the estimation of smoke exposure of individuals it is fundamental to a have a good knowledge of the spatial distribution of air pollutant concentrations. These are dependent on the fire progression, which is a function, among other factors, of the wind flow characteristics. The modelling approach developed in this work integrates the referred components by using specific models available in the literature. These models have been previously linked and tested by Valente et al. [4]:

- meteorological model NUATMOS [5];

- $\quad$ fire progression model FireStation [6];

- $\quad$ smoke dispersion model DISPERFIRE [7].

An exposure module was developed and linked to these numerical tools as schematically shown in Figure 5.

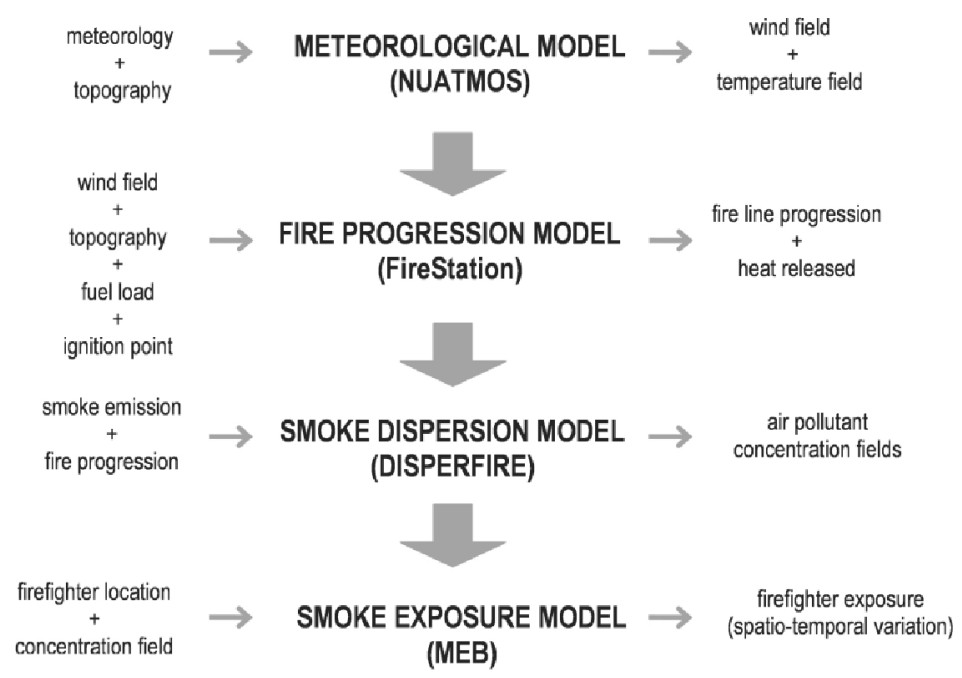

Figure 5: Schematic representation of the exposure modelling approach.

This numerical system implies a chain of data from one model to another, starting with the meteorological spatio-temporal fields until the last expected 
outcome, which is the spatial-temporal distribution of firefighters' exposure to smoke.

\subsection{Meteorological model NUATMOS}

The diagnostic wind model NUATMOS [5] produces a three dimensional (3D) mass consistent wind field through the interpolation of observations arbitrarily located throughout the domain of interest. The atmospheric stability is taken into account through an input parameter, which is related to the Froude number, and determines the adjustment made to the vertical component relative to the horizontal adjustment during the divergence-free solution phase. The numerical equations are solved in terrain-following coordinates and variable vertical grid spacing. This model has already been tested for this area with good results $[4,8]$.

\subsection{Fire progression model FireStation}

FireStation [6] is software aimed at the simulation of fire spread over complex topography. It implements five distinct mathematical models for the simulation of the rate of spread, fire shape, fire growth, fire weather index and wind field. The fire behaviour model is based on the Rothermel's surface fire spread model [9], and has as inputs local terrain slope, parameters describing fuel properties, and wind speed and direction. The fire shape is described using two ellipse type models: one proposed by Anderson [10] and the other by Alexander [11]. Both take as input the wind speed at mid-flame height. In terms of implementation, the fire growth is carried out using a raster approximation. The topography is divided into cells, over which fuel properties are assumed constant. The fire growth simulation thus becomes a contagion process between burning and nonburning cells. This process, based on the Dijkstra's dynamic programming algorithm, leads to a time progression that may not be constant [6].

\subsection{Smoke dispersion model DISPERFIRE}

DISPERFIRE [7] is a real-time system developed to simulate the dispersion in the atmosphere of the pollutants emitted during a forest fire. Particles are tracked by using a 3D Lagrangian approach. The smoke plume height (injection height) is estimated using the Sestak and Riebau [12] methodology. One of the limitations of this model is that it does not consider the two-way coupling between the fire and the atmosphere, i.e., the wind speed and direction affects the fireline dynamics and corresponding emissions, but there is no effect of the heat over the wind flow. Its application if therefore specifically adequate for small scale burns.

\subsection{Smoke exposure model MEB}

It is important to distinguish concentration and exposure. While the first is a physical characteristic of the environment at a given place and time, the latter quantifies the interaction between the polluted atmosphere and the person [13]. 
The exposure model was developed specifically under the current work with the objective of providing the estimate of the individual exposure of firefighters, but it can be used also in other environments (outdoor, indoor, or a combination of both).

In the core of MEB is the calculation of the individual exposure through the following general expression (which is a simplification of the microenvironment approach from Hertel et al. [14] since in this case only one microenvironment exists):

$$
\exp _{i}=C_{i} \times t_{i}
$$

where $\exp _{i}$ is the total exposure for firefighter $i$ over the specified period of time; $C_{i}$ is the pollutant concentration in a given location, and $t_{i}$ is the time spent by firefighter $i$ in that specific location. As a result, the exposure value is expressed in concentration $\times$ time, and thus can be interpreted as the mean pollutant concentration value to which the firefighter has been exposed during a given period of time.

Therefore, by crossing, for each time-step $(\Delta t)$, the georeferenced positioning of the firefighter $(\Delta t=5 \mathrm{~s})$ with the corresponding concentration on that location and time $(\Delta \mathrm{t}=60 \mathrm{~s})$, the model simulates the time evolution of the exposure. The output data produced by MEB is the following:

- 1 minute individual exposure values;

- average exposure in a given period of time.

\section{Application of the smoke exposure modelling system}

The developed system was applied to simulate the firefighter exposure during the burning of plot P02. The input data for this numerical tool are the following:

- the temporal variation of firefighter location: this information is provided by the GPS equipment with a temporal resolution of $5 \mathrm{~s}$;

- the temporal variation of the spatial distribution of concentrations at a height of $1.6 \mathrm{~m}$ (considered as a typical average inhalation height): these data are estimated by the DISPERFIRE model with a temporal resolution of $60 \mathrm{~s}$.

Even using local meteorological conditions data, detailed fuel characterisation, and topographic profiling, the fire progression model takes about half the time to consume the entire plot when compared to our measurements, probably because of firefighters' intervention controlling the burning. In terms of emissions, this discrepancy means that more fuel is consumed per time interval, causing an overestimation of the amount of air pollutants emitted along the time. In order to overcome this problem, and its influence over the estimation of the individual exposure, we have tuned the dispersion model in order to have the lowest error possible in comparison with the observations at the location of the air quality laboratory. Table 2 presents the comparison between final simulated $\mathrm{CO}$ concentration values and those measured at the mobile laboratorial van during the first 4 minutes of plot P02 burning 
Table 2: $\quad$ Comparison between computed and measured $\mathrm{CO}$ concentration at the location of the mobile air quality laboratory.

\begin{tabular}{ccc}
\hline $\begin{array}{c}\text { Time after } \\
\text { ignition }(\mathrm{min})\end{array}$ & \multicolumn{2}{c}{$\mathrm{CO}\left(\mu \mathrm{g} \cdot \mathrm{m}^{-3}\right)$} \\
\hline 1 & 2,912 & 2,908 \\
2 & 4,705 & 4,748 \\
3 & 3,694 & 3,701 \\
4 & 7,009 & 7,060 \\
\hline
\end{tabular}

The simulated behaviour of the smoke plume during the burnings is shown in Figure 6. Each image represents the spatial distribution of 1 minute averaged $\mathrm{CO}$ concentration.
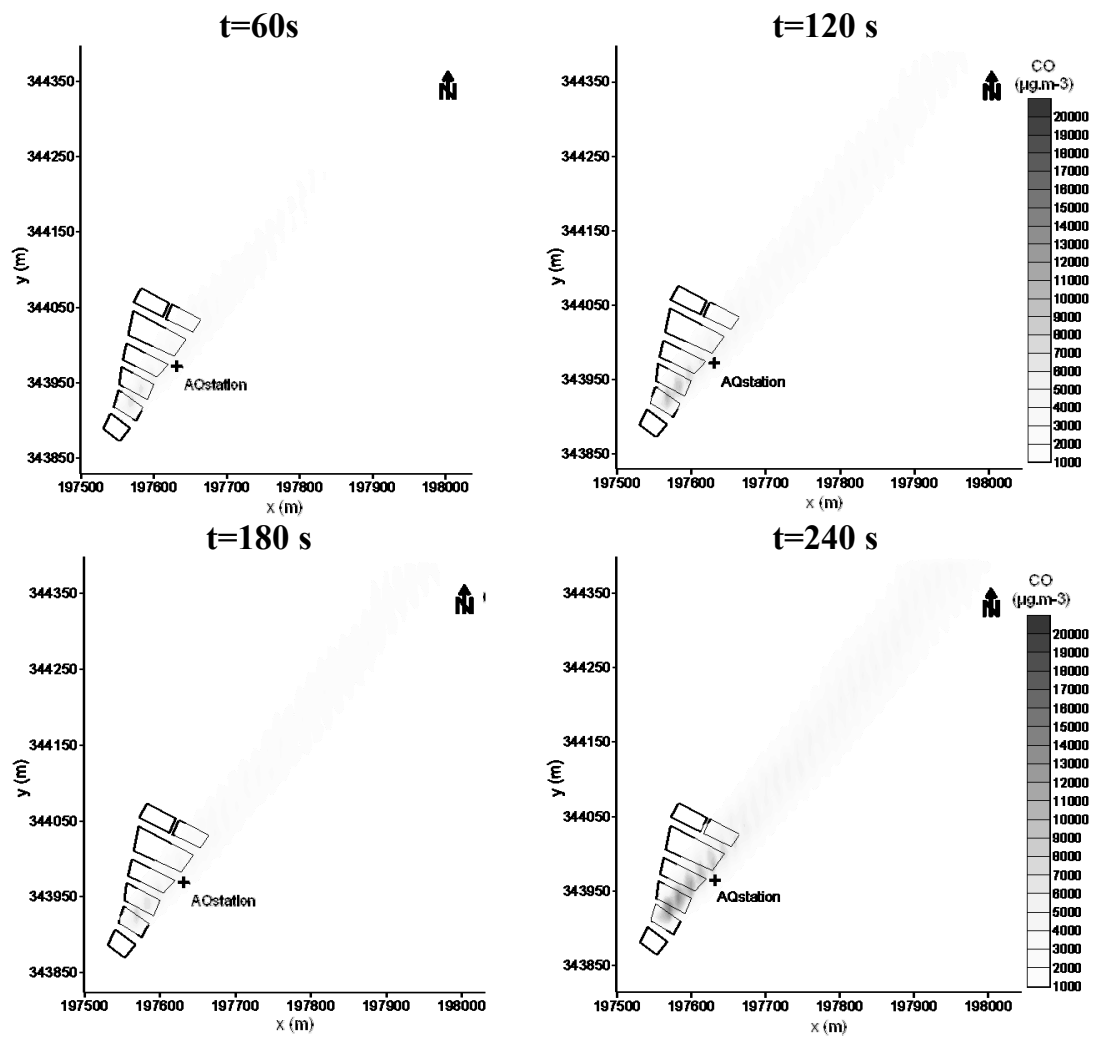

Figure 6: Spatio-temporal distribution of $\mathrm{CO}$ concentration values according to DISPERFIRE simulations for plot P02. The cross represents the location of the air quality monitoring station. 
From the concentrations computed with DISPERFIRE it was then possible to proceed to the estimation of the firefighter exposure following the approach schematically shown in Figure 5. Figure 7 shows the 1 minute temporal evolution of measured and calculated firefighter exposure values for the first 4 minutes of the burning.

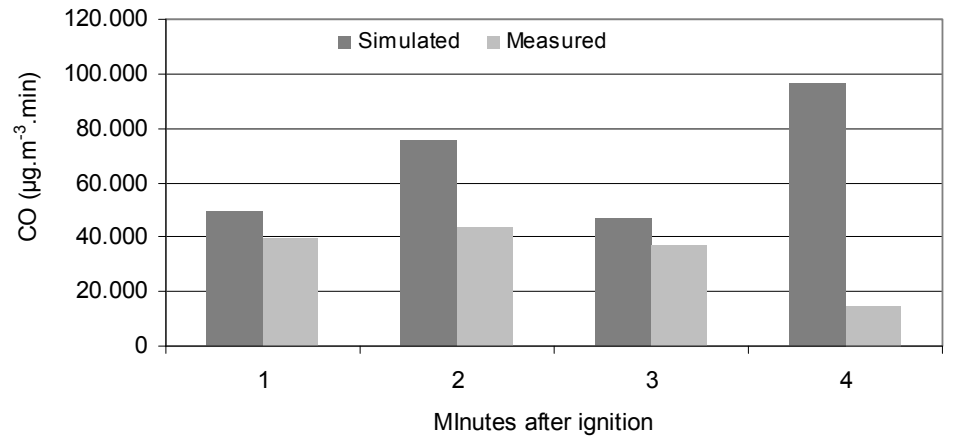

Figure 7: $\quad$ Firefighter simulated and measured exposure values $\left(\mu \mathrm{g} \cdot \mathrm{m}^{-3} \cdot \mathrm{min}\right)$ during the first 4 min of plot P02 burning.

In general exposure simulated values are higher than measured ones, but with the exception of the fourth minute data the agreement is quite good. This large disagreement for the fourth minute estimation can be related to the sudden decrease of measured exposure between the third and the fourth minutes (see Figure 4), which was not simulated by the modelling system.

The mean exposure estimated by MEB for this specific firefighter and for the total burning period was $6,716 \mu \mathrm{g} \cdot \mathrm{m}^{-3} . \mathrm{min}$, which is in very good agreement with the measured mean exposure value of $5,837 \mu \mathrm{g} \cdot \mathrm{m}^{-3} \cdot \mathrm{min}$.

\section{Conclusions}

It is generally accepted that firefighters are potentially exposed to critical levels of air pollution during suppression activities (both in direct combat and mop-up), but the concentrations attained in the breath zone of firefighters' intervening in forest fires or prescribed burning are still scarcely quantified. We have tested the possibility of inferring the exposure level of a firefighter in a given instant in time by cross-walking simulated smoke patterns with geo-location. The comparison with results from the developed MEB model with observed exposure data is promising.

However, there is still a limited understanding of the air quality levels close to the fireline and we need a better understanding of the complex and dynamical conditions faced by firefighters in real suppression operations. In fact, the complexity inherent to the simulation of the emission and dispersion of smoke with the spatial and time scales shown in this analysis is significantly high. In a 
real fire situation, the main sources of error are related with inadequate characterisation of fuel and local meteorological conditions which can potentially compromise the accuracy of fire progression simulation and the estimation of fuel consumption and smoke emissions.

The information on the individual exposure of firefighters can support the management of the crew positioning by anticipating potentially critical exposure levels and recommending safer routes for the attack. Thus this type of modelling activities can be an added value to avoid firefighters' exposure to toxic smoke compounds.

\section{Acknowledgements}

The authors would like to acknowledge the financial support of the $3^{\text {rd }}$ European Framework Program and the Portuguese Ministry of Science, Technology and Higher Education, through the Foundation for Science and Technology (FCT), for the funding of the National research project FUMEXP (PTDC/AMB/66707/2006), the Post-Doc grants of J.H. Amorim (SFRH/BPD/48121/2008) and J. Valente (SFRH/BPD/78933/2011), and the PhD grant of V. Martins (SFRH/BD/39799/2007).

\section{References}

[1] Reinhardt, T.E. \& Ottmar, R.D. Baseline measurements of smoke exposure among wildland firefighters. J Occup Environ Hyg 1, 593-606, 2004.

[2] Reisen, F. \& Brown, S.K. Australian firefighters' exposure to air toxics during bushfire burns of autumn 2005 and 2006. Environment International 35, 342-52, 2009.

[3] Miranda, A.I., Martins, V., Cascão, P., Amorim, J.H., Valente, J., Tavares, R., Borrego, C., Tchepel, O., Ferreira, A.J., Cordeiro, C.R., Viegas, D.X., Ribeiro, L.M. \& Pita, L.P. Monitoring of firefighters exposure to smoke during fire experiments in Portugal. Environment International 36, 736$745,2010$.

[4] Valente, J., Miranda, A.I., Lopes, A.G., Borrego, C., Viegas, D.X. \& Lopes, M. Local-scale modelling system to simulate smoke dispersion. Int $J$ Wildland Fire 16 (2), 196-203, 2007.

[5] Ross, D., Smith, I., Manins, P. \& Fox, D. Diagnostic wind field modelling for complex terrain: model development and testing. Journal of Applied Meteorology 27, 785-796, 1988.

[6] Lopes, A.M.G., Cruz, M.G. \& Viegas, D.X. FireStation - an integrated software system for the numerical simulation of fire spread on complex topography. Environmental Modelling \& Software 17, 269-285, 2002.

[7] Miranda, A.I., Borrego, C. \& Viegas. D.X. Forest fire effects on the air quality. In 'Air pollution II, computer simulation'. (Eds J.M. Baldasano, C.A. Brebbia, H. Power, P. Zannetti) pp. 191-199. (Computational Mechanics Publications: Southampton, UK), 1994. 
[8] Borrego, C., Carvalho, A.C. \& Miranda, A.I. Numerical simulation of wind field over complex terrain. In 'Measuring and modelling investigation of environmental processes'. (Ed. R. San Jose) pp. 271-298. (WIT Press: Southampton, UK), 1999.

[9] Rothermel, R.C. A mathematical model for predicting firespread in wildland fuels. USDA Forest Service Research Paper INT-115. (Ogden, UT), 1972.

[10] Anderson, H.E. Predicting wind-driven fire size and shape. USDA Forest Service Research Paper INT-305. (Ogden, UT), 1983.

[11] Alexander, M.E. Estimating the length-to-breadth ratio of elliptical forest fire patterns. In 'Proceedings of the eighth conference on fire and forest meteorology'. pp. 287-304. (Society of American Foresters: Bethesda, MD), 1985.

[12] Sestak, M.L. \& Riebau A.R. SASEM - Simple Approach Smoke Estimation Model. US Department of the Interior, Bureau of Land Management Technical Note 382. (Denver, CO), 1988.

[13] Ott, W.R. Concepts of human exposure to air pollution. Environment International 7, 179-196, 1982.

[14] Hertel, O., Leeuw, F.D., Raaschou-Nielsen, O., Jensen, S.S., Gee, D., Herbarth, O., Pryor, S., Palmgren, F. \& Olsen E. Human exposure to outdoor air pollution - IUPAC Technical Report. Pure Appl. Chem., 73 (6), 933-958, 2001. 